\title{
FORCES AND DISPLACEMENTS DISTRIBUTION AFTER FEM ANALYSIS OF VIBRATORY WORKING TOOL
}

\author{
NELUS-EVELIN GHEORGHITA*1 \\ ${ }^{I}$ Department of Biotechnical Systems, Politehnica University of Bucharest, Romania
}

\begin{abstract}
The research status and the study of vibratory working tools used in tillage operations are discussed in this paper. At this moment, one of the most critical issues for the engineers and manufacturers is to achieve the highest efficiency with the least resources needed. Various studies by researchers on vibratory working tool styles and models have been taken into account. A study was then conducted to ascertain the advantages of vibratory equipment over rigid equipment. A finite element process study was also conducted on one active working tool to observe specific deformations and displacements. Draft forces ranging from 440 to $750 \mathrm{~N}$ were used in the study. According to prior studies, the angle of attack after the forces have been applied should not exceed 80 degrees.
\end{abstract}

Keywords: vibratory equipment, draft force, finite elements method

\section{INTRODUCTION}

Because the unique resistance of the soil varies continually during work with active working tools mounted on elastic supports, the supports vibrate longitudinally, exerting a higher action on the soil layer, favoring its weakening and loosening. Depending on the soil humidity and the frequency of the oscillating movement, the vibration of the tillageworking tool causes a low coefficient of external friction between the soil and the active surface of the tool [1].

Compared to non-oscillating tools, vibratory tools have many advantages. Also, compared to non-oscillating tools, oscillating tools need less draft force [2]. As a result, the problems associated with tillage applications can be solved using a vibratory tillage tool. Active working tools of dimensions $40 \times 40$, made of steel, have a high resistance to shock and dynamic loads, having a wide variety of adaptable cutting tips.

The application of vibrations allows to increase working speeds mainly due to the reduction of energy consumption required to perform the work itself, but also because of eliminating the need to perform intermediate processes or adjacent to the basic process or reduce their share in the basic process, thus contributing to increasing the productivity of agricultural machinery [3].

FEM analysis of structures has become a necessity [4] to simplify and decrease the expense of testing in operation or under simulated and accelerated regimes. It can approximate the regions of maximum (critical) stress [4, 5], the maximum stress, and even how much time a structure would resist within adequate accuracy. Because of the trend toward wider working widths, the tractor wheel ability to transform power into working with the drawbar is becoming increasingly problematic, especially with the decreased slip of the tire surface.

\footnotetext{
*Corresponding author, email: evelin_gheorghita@yahoo.com
}

(C) 2021 Alma Mater Publishing House 
This stage of production produces a high fuel consumption, which accounts for a big part of the total production costs, depending on the intensity of the cultivation work [6].

The constructive solution of one vibratory working tool was investigated using the Finite Element Method for a specific angle of attack and various draft force values. Soil processing tools are often used to perform several processes at once, such as displacement, stretching, compression, bending, and twisting. [7] The physical properties of the soil, the exploitation characteristics of the agricultural aggregates, and the geometric specifications of the working tools all affect the amount of energy available for soil tillage [8].

Mechanical soil processing is a time-consuming and energy-intensive process. The aim of soil processing is to modify the apparent density, granulometric composition of aggregates, and other attributes to create optimal conditions and an atmosphere conducive to crop plant growth [9].

The objective of the paper is to analyze if the forces, calculated for the vibratory tool, can be applied without appearing a failure. And if that happens, the design of the tool should be modified for obtaining the best results. Another objective of this discussion is to find the dynamic parameter, so that the vibration of the working tool can reduce the force required to reduce the density of the soil during its processing operation.

\section{EXPERIMENTAL SETUP}

\subsection{The vibratory working tool}

The working tool chosen for the study, presented in Figure 1, is part of a vibro-cultivator, which operates in in both dry agricultural soil and in that with more precipitation. The width of the models in the product ranges from 4.1 to 8.7 meters [10].
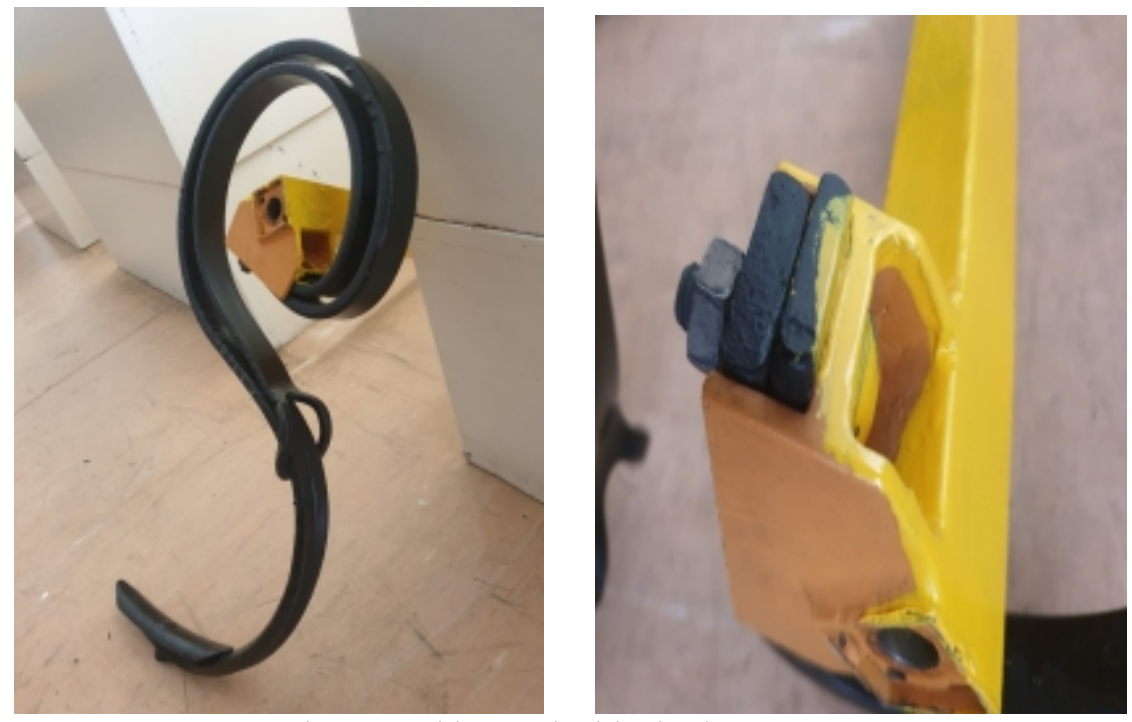

Fig.1. Working tool with elastic support.

For the analysis was used Simulation module from SolidWorks software. Figures 2 and 3 show the calculation model that was used for the meshing and contour conditions. The forces are applied perpendicularly, and the fixtures are at the top of the model. 


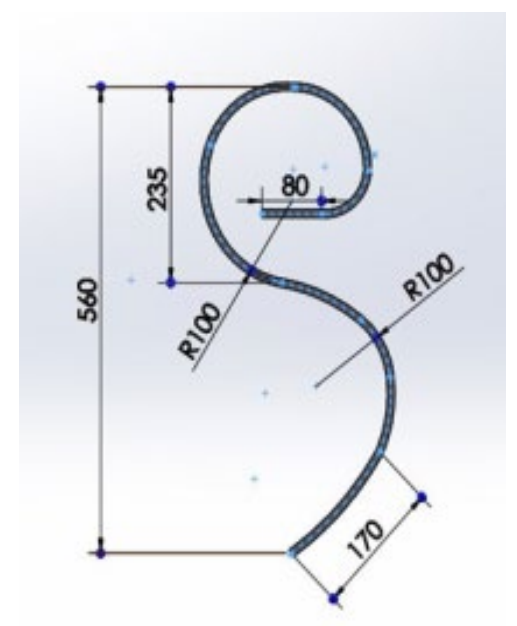

Fig. 2. 3D model and dimensions of working tool with elastic support.

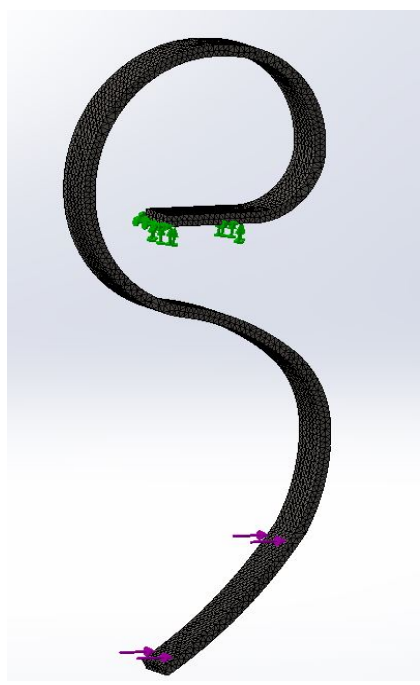

Fig. 3. Mesh, fixtures and loads of the model.

\subsection{Parameters calculated using Mathcad}

The specific resistance of the soil to deformation appears in many reference materials, such as, for example in Goreacikin's formula, for the calculation of the resistance to plowing, extensible to other soil works:

$$
R(f, k, \varepsilon p, \rho):=f \cdot G+k \cdot S+\varepsilon p \cdot \rho \cdot S \cdot v^{2}
$$

For the first calculation of the specific resistance of the soil to deformation, the following parameters and the ones in Table 1 were used:

- $\quad$ working speed, $\mathrm{v}=5 \mathrm{~km} / \mathrm{h}(1.389 \mathrm{~m} / \mathrm{s})$;

- mass of the cultivator, $\mathrm{m}=2100 \mathrm{~kg}$;

- active surface on which the traction force acts, $\mathrm{S}=0.0125 \mathrm{~m}^{2}$;

- $\quad$ soil density, $\rho=1100 \mathrm{~kg} / \mathrm{m}^{3}$;

- number of vibrating working tools, $\mathrm{n}=65$.

Table 1. List of parameters for the calculation of vibratory tool.

\begin{tabular}{|l|l|c|c|c|}
\hline No. & Name & Notation & Unit of measure & Selected value \\
\hline 1 & $\begin{array}{l}\text { Specific resistance to soil } \\
\text { deformation }\end{array}$ & $\mathrm{k}$ & $\mathrm{N} / \mathrm{m} 2$ & $6^{*} 104$ \\
\hline 2 & $\begin{array}{l}\text { Constant resistance given by the } \\
\text { speed of movement of the active } \\
\text { tool in the soil }\end{array}$ & $\varepsilon$ & $\mathrm{Kg} / \mathrm{m}^{3}$ & 1.393 \\
\hline 3 & Working depth & $\mathrm{a}$ & $\mathrm{m}$ & 0.1 \\
\hline 4 & Working width & $\mathrm{b}$ & $\mathrm{m}$ & 4.95 \\
\hline 5 & Working speed & $\mathrm{v}$ & $\mathrm{m} / \mathrm{s}$ & 1.389 \\
\hline
\end{tabular}

The calculations resulted in a minimum traction force of Fmin $=269.19 \mathrm{~N}$, an average force Fmed $=728 \mathrm{~N}$ and a maximum force $\mathrm{Fmax}=1253 \mathrm{~N}$, for the working speed $\mathrm{v}=5 \mathrm{~km} / \mathrm{h}$. 


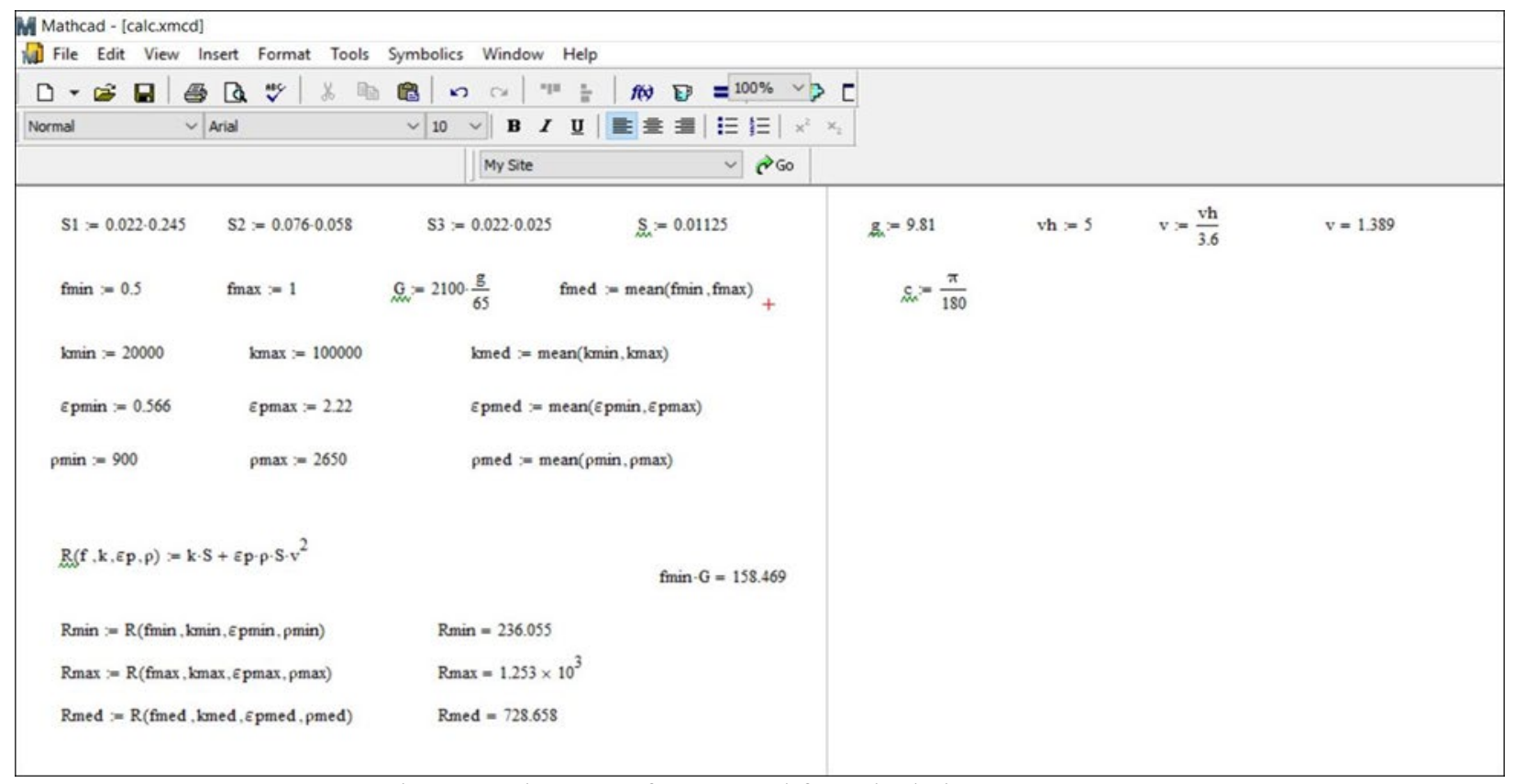

Fig. 4. MathCAD software used for calculating parameters.

Different values for the force $\mathrm{F}$ determined with the Mathcad software $(400,500,600,750 \mathrm{~N})$ were used for this constructive solution and results, as shown in Figure 4. FEM has been used to analyze deformations and stress. The maximum force calculated, $1253 \mathrm{~N}$, could not be reached on the model because the deformations were too big.

\section{RESULTS AND DISCUSSION}

The Figures 5, 6, 7 and 8 indicate the effects of the support's FEM study. They show the distribution of equal stress based on the Von-Mises criterion for four values of draft force $\mathrm{F}$, as well as the distribution of total displacements for the form of support. During the simulation, a maximum Von Misses stress of $710.7 \mathrm{MPa}$ was reported in the upper part of the arc, as predicted, with a limit of $620 \mathrm{MPa}$.
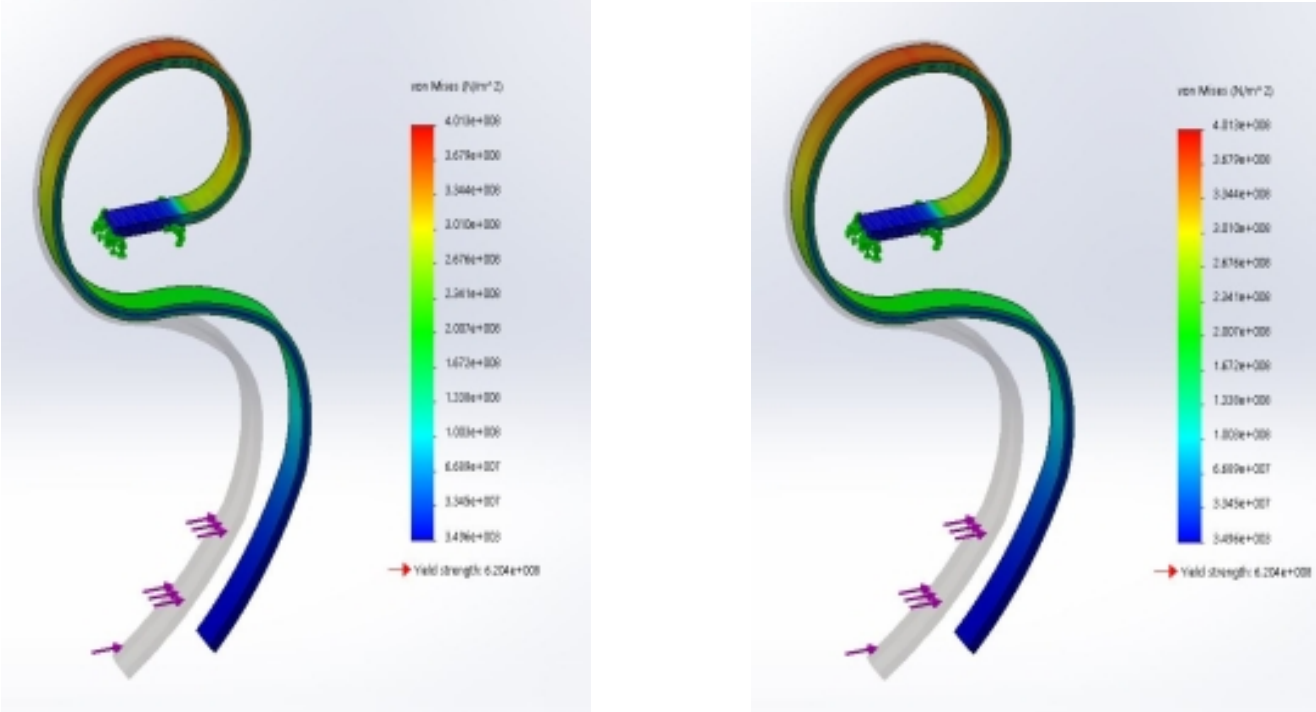

Fig. 5. The distribution of stress and displacements at a draft force of $F=400 \mathrm{~N}$. 

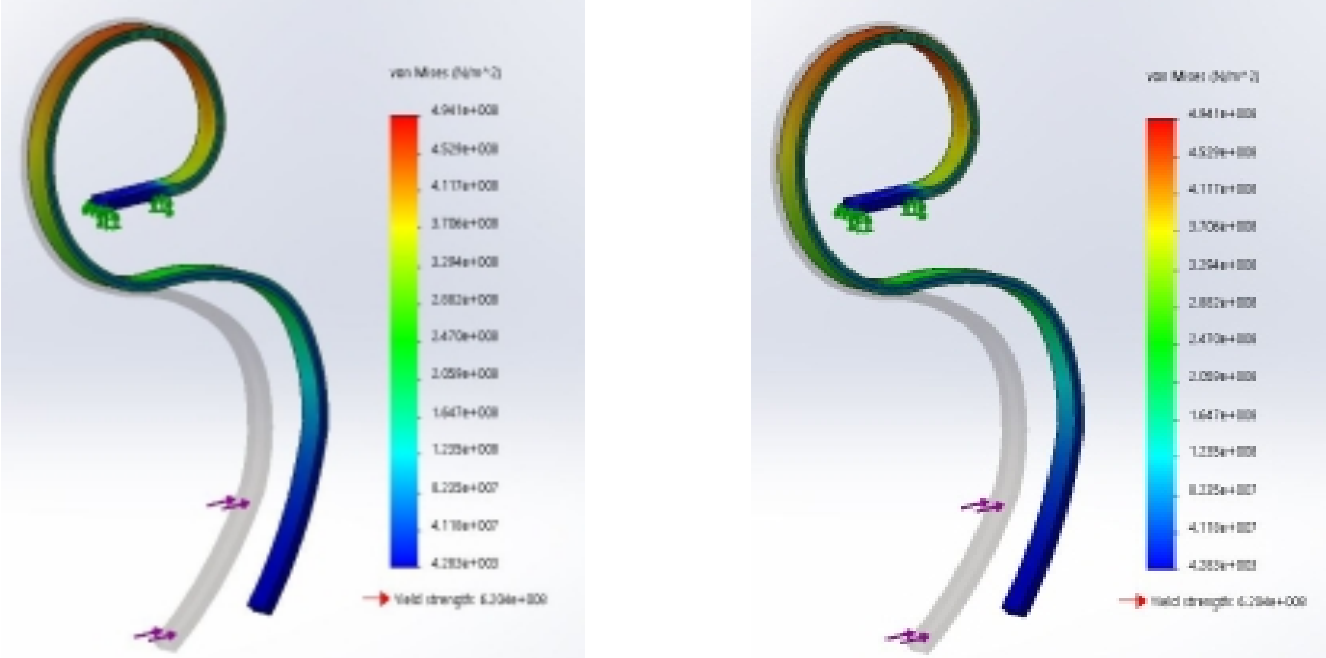

Fig. 6. The distribution of stress and displacements at a draft force $F=500 \mathrm{~N}$.
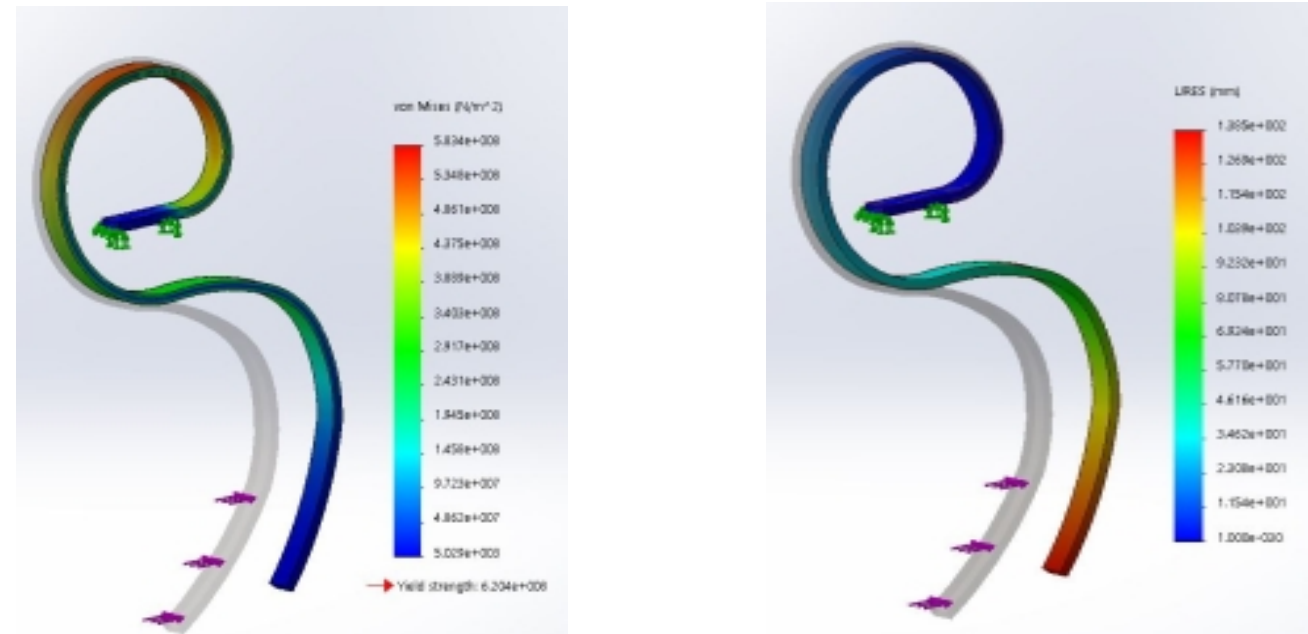

Fig. 7. Distribution of stress and displacements at a draft force $\mathrm{F}=600 \mathrm{~N}$.
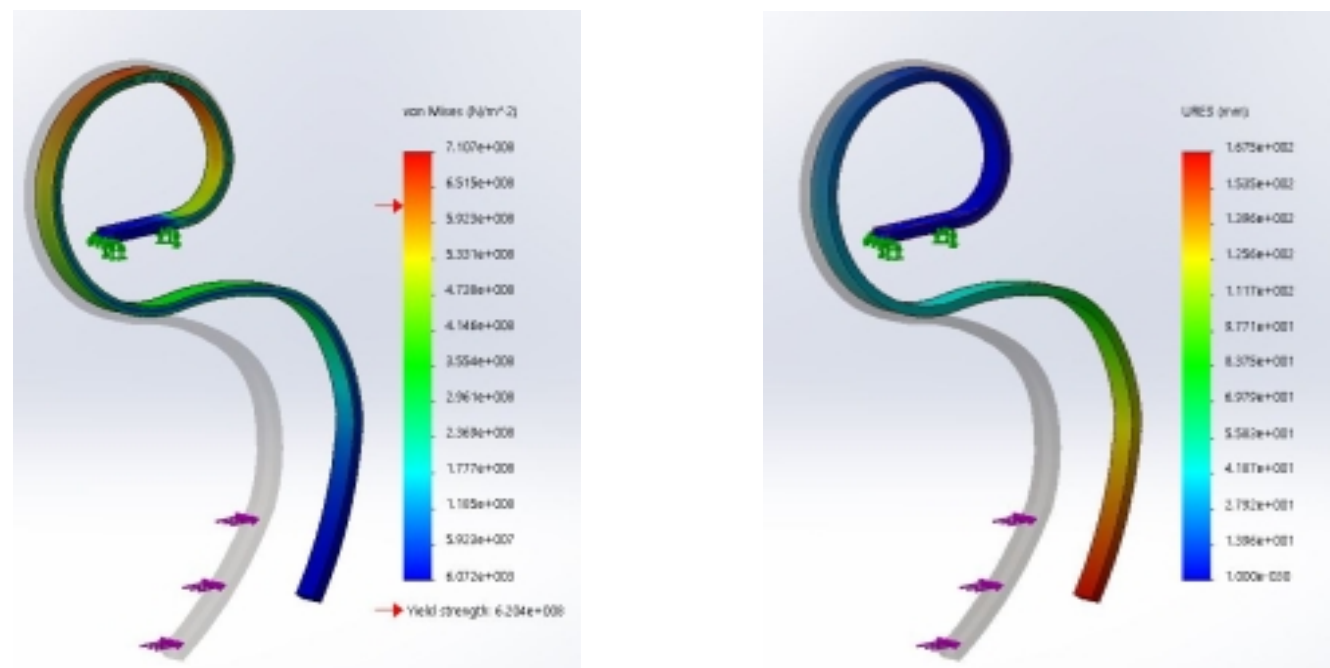

Fig. 8. The distribution of stress and displacements at a draft force $F=750 \mathrm{~N}$. 


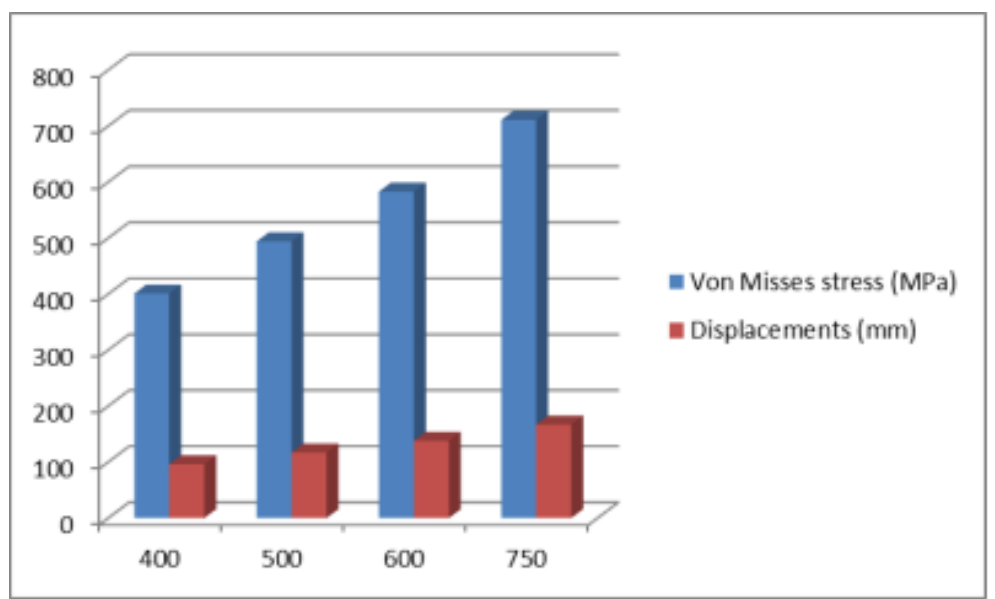

Fig. 9. Variation of stress and displacements.

In Figure 9 is show the variation of stress and displacements. As the draft forces are higher, the deformations are higher, up to a point where the limit is exceeded. These are the values for a working speed of $5 \mathrm{~km} / \mathrm{h}$. From previous studies it was recommended that the angle of attack $\beta$ should not exceed values of about $80^{\circ}$ after the forces have been applied. Like we see in Figure 8, after a force of $750 \mathrm{~N}$ have been applied, that angle have been exceeded, and could exist the danger of the working tool to come out of the soil. In the past studies on the same working tool but with higher speeds applied in the calculus, the angle has been exceeded with even lower forces, so the speed of $5 \mathrm{~km} / \mathrm{h}$ appears to be the most optimal.

\section{CONCLUSIONS}

During the simulations, in which the calculation of the working parameters was done at only one speed of the cultivator, it turned out that the maximum tension was recorded as expected in the upper part of the tool. The maximum displacements were observed near the area where the force acts, having values within normal limits, but the maximum force calculated could not be applied.

The highest equivalent stress for a draft force of $750 \mathrm{~N}$ exceeds the material's maximum, (Figure 8). The highest values that needed to be reached are about $620 \mathrm{MPa}$, and the maximum stress on the support is $710.7 \mathrm{MPa}$. Displacements can also exceed a maximum of $167 \mathrm{~mm}$. If $\mathrm{F}$ is greater than $750 \mathrm{~N}$, the attack angle will reach values of $75-80^{\circ}$, which indicate the upper limit for ensuring good stability for the tool in the soil, and the active tool will come out of the soil.

Future research should concentrate on deciding the optimal oscillation angle for draft reduction and low power consumption, as well as determining whether an additional support can be added to the current tool for increasing those limits. Also, further analysis should be made at different speeds of the cultivator to see potential effects.

\section{ACKNOWLEDGEMENT}

This work has been funded by the European Social Fund from the Sectoral Operational Programme Human Capital 2014-2020, through the Financial Agreement with the title "Scholarships for entrepreneurial education among doctoral students and postdoctoral researchers (Be Antreprenor!)", Contract no. 51680/09.07.2019 - SMIS code: 124539.

\section{REFERENCES}

[1] Kattenstroth, R., Harms, H.-H., Wurpts W., Twiefel J., Reducing friction by ultrasound treatment exemplified by tillage, VDI-MEG Tagung Landtechnik, 06-07.11.2009, Hannover. In: VDI-Berichte 2060, VDIVerlag, Dusseldorf, 2009, p. 259-264.

[2] Gowripathi, R., Himanshu, C., A review on effect of vibration in tillage application, IOP Conference Series: Materials Science and Engineering, 2018. 
[3] Cultivators and harrows for all soil types, 2015, VaderstadAB, Sweden, https://www.vaderstad.com/uk/tillage/tine-cultivators/swift-400-870/.

[4] Duarte, C.A., Hamzeh, O.N., Liszka, T.J., TworzydloW.W., A generalized finite element method for the simulation of three-dimensional dynamic crack propagation, Computer methods in applied mechanics and engineering, no. 190, vol. 15-17, 2001, p. 2227-2262.

[5] Bhatti, M.A., Finite element analysis. Theory and applications, Zephyr copier, Iowa State University, 2003.

[6] Kattenstroth, R., Harms, H.H., Lang, T., W.s, W., Twiefel, J., Wallaschek, J., Reducing friction in tillage using ultrasonic vibration, 2010.

[7] Gheres, M.I., Cercetari privind optimizarea parametrilor geometrici si funcţionali ai sculelor de lucrat solul in vederea reducerii consumului de energie, Teza de doctorat, Universitatea Tehnica din Cluj-Napoca, 2001.

[8] Fechete, T.L.V., Ros, V., Coța, C., Nagy, M., Optimizarea paramerilor geometrici ai unei scule active de lucrat solul, Acta technica napocensis Series: applied mathematics and mechanics, vol. v, no. 50, 2007, p. 461-464.

[9] Ivan, I., Deac, T., Analiza posibilitaţilor de crestere a randamentelor agricole in Romania, Acta technica napocensis series: applied mathematics and mechanics, vol. V, no. 50, 2007, p. 457-460.

[10] Gheorghita, N.E., Biris, S. St., Influence of the attack angle on the performance of vibratory cultivators, Journal of research and innovation for sustainable society (JRISS), vol. 1, no. 1, 2019, p. 91-96. 